\title{
Geomagnetic Oriented Electromagnetic Radiation in the lonosphere
}

by
C. U. Benton
H. M. Fowles"
P. K. Goen**

*University of Denver, 2199 S. University Blvd., Denver, CO 80210

* Sandia Laboratories, Albuquerque, NM 87115 
Printed in the United States of America. Available from National Technical Information Service

U.S. Department of Commerce

5285 Port Royal Road

Springtield, VA 22161

Price: Printed Copy \$3.50 Microliche $\$ 2.25$

Thin repont end prepared an on ecrount of worth pponeored

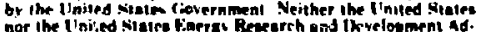

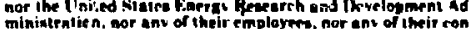

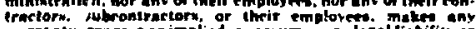

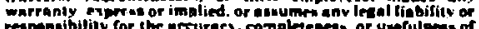

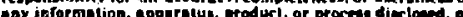

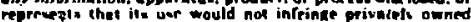
rithin. 
GEOMAGNETIC ORIENTED ELECTROYAGNETIC RADIATION IN THE IONOSPHERE

by

C. U. Benton, H. M. Fowles, and P. K. Goen

\section{ABSTRACT}

Strong bursts of electromagnetic radiation were observed in the fonosphere during the Waso rocket Electromagnetic Pulse (DMP) experiment. The pulses have a frequexcy content from below $20 \mathrm{MHz}$ to above $70 \mathrm{MHz}$. They vary in duration between $5 \mu \mathrm{ss}$ and 2 ms and in peak-amnlicudes of $2 \mathrm{mV} / \mathrm{m}$ to greater than 200 $\mathrm{mV} / \mathrm{m}$. These pulses show a high degree of geomagnetic corkelation and are of unknown origin.

\section{INTRODUCTION}

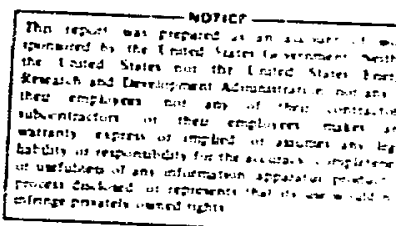

One of the objectives of the Waso Electromagnetic Pulse (EMP) experiment was to measure the electromagnetic background in the lonosphere. A Terrler Sandhawk rocket system with a $22.9-\mathrm{cm}-\mathrm{d}$ lam payload, $351 \mathrm{~cm}$ long, was used. The payload reached an apogee of $405.5 \mathrm{~km}$ at $319 \mathrm{~s}$. Data were taken continuously on most systems from launch to reentry at $612 \mathrm{~s}$. The Langwuir probes and the scan converter took data only when the payload was above $90 \mathrm{kr}$.

\section{INSTRUMENTATION}

The EMP instrumentation consisted of three EMP antennas, two of which drove three filter channels each. The six filter channels continuously recorded the electromagnetic flelds seen by the payload. Each channel had 6-MHz bandwidth and the center frequencies were spaced at 10- $\mathrm{HHz}$ intervals from 20 through $70 \mathrm{MHz}$. The envelopa of the recelved signal was continuously teiemetered to the ground on an S-band carrier.

The third antenna furnished signals to a scan cunverter system which had a 3-db bandwidth from $1 \mathrm{MHz}$ to $300 \mathrm{MHz}$. The scan cenverter provided a time domain record of 3.3-us length of any signal above a preset threshold that arrived when 
the scan converter was armed. After being triggered, 5 s were required to transwit the recetved signal before the scan corverter was automatically rearmed.

Supporting instrumentation included dual Langmulir probes to measure in situ electron densities; a magnetometer to provide information on rocket ortentation; two S-band celemetry systems; an electronic sequencer; a fire-module system; a radar cransponder; a payload recovery bystem which included a C-band beacon.

Ground station equipment consisted of two tracking ridars, two S-band receivers with tracking antennas, three tape recorders, a time code system, a scan converter base station, launci control, prelaunch payload control, and a 2-mV pulser.

III. PREFLIGHT INVESTIGATIONS

The 2-mV pulser was located $300 \mathrm{~m}$ from the launcher and produced a nominaI peak field of $4.8 \mathrm{kV} / \mathrm{m}$ at $100 \%$. The radiated field was mapped $1 \mathrm{n}$ aztauch and elevation using a callbrated sensor suspended $100 \mathrm{~m}$ below a helicopter. Tests were conducted to insure safery of the rocket motors and inftiacors locared nearby. The pulser was operated at various intervals in the $24-h$ day for a 3-wk perlod and lonograms taken before, during, and after the pulser operacion in order to search for posstble lonosphere modiflcation effects. No significant effects were found, (1.e., changes that could not have been caused by ncher means).

\section{FLIGHT SUNMARY}

Prior to launch day, full oyscems cests 1ndicated proper operation of all systens. Prelaunch tests began $2 \mathrm{~h}$ before launch and the rocket was launched on schedule at Barking Sands, Kaual, Hawa11 at 1400 UT on May 9, 1975. The tocket performance during the flight was swooth and followed closely the predicted trajectory. Apogee was at $+319 \mathrm{~s}$ at an aicitude of $405.5 \mathrm{~km}$. Coning angle of the payload was $\pm 2.8^{\circ}$ and the payload roll rate was 4.4 rps. Normal nolse was experlenced on all celemetry channels during the burn phase of the first and second stages. All telemetry channels returned to normal at $+35 \mathrm{~s}$ at an altitude of $94 \mathrm{kn}$ when the Langrulr probeg were deployed. The scan converter operation tegan at ahout the same the. Data vere obtalned unt $11+612 \mathrm{~s}$ at an alcleude of $41 \mathrm{~km}$.

The 2-mV pulser was operated in approximeely 16-s intervals begining at $+58.475 \mathrm{~s}$ and continued unt $11+639 \mathrm{~s}$. The payload was recovered in a normal fashion and all equipment was found to operace properiy except the magnetomeler and Langmuit probes which were destroyed on reentry. 


\section{v. ANALYSIS SUMMARY}

All celemetry, radar data, time codes, and voice commentary were tape recorded in real time. Immediately after splashdown, osclilograms were made at slow speed from the tapes. Proper operation of the system during the flight was indicated. The Langmuir probe data were reduced to give electron density (Ne; profiles of a weak, stable lonosphere. The Ne proflle frim the Langmulr probes compared veiy closely with predicted Ionogonde derived profiles (Figs. 1 and 2).

Short pulses were observed on the ftlter channels which did not correlate with pulses from the pulser. The scan converter triggered repeatedly within 10 ms after arming. None of the scan converter data resembled pulses from the 2-mV pulser and trigger-times were not correlated with pulser firing. Many of the scan converter traces display an apparent monochromatic or CW-1ike signal in the VHF range or possibiy of higher frequency. The observed signals correspond to a field of $\sim 100 \mathrm{mV} / \mathrm{m}$ which is higher than previously reported estimates of lonospheric EM background. 1-3

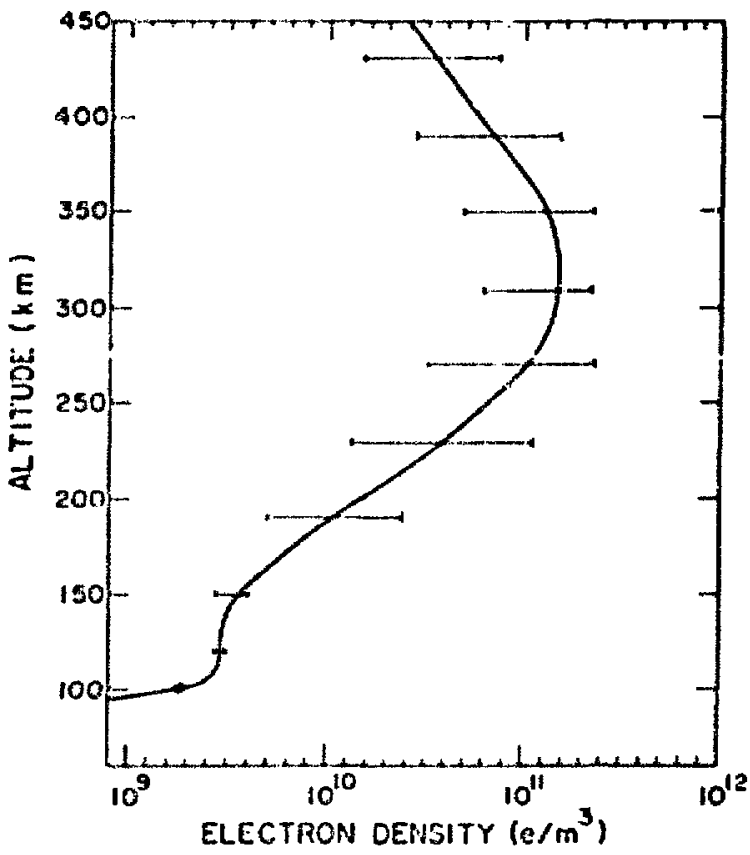

Fig. 1. Calculated Electron Density Profile.

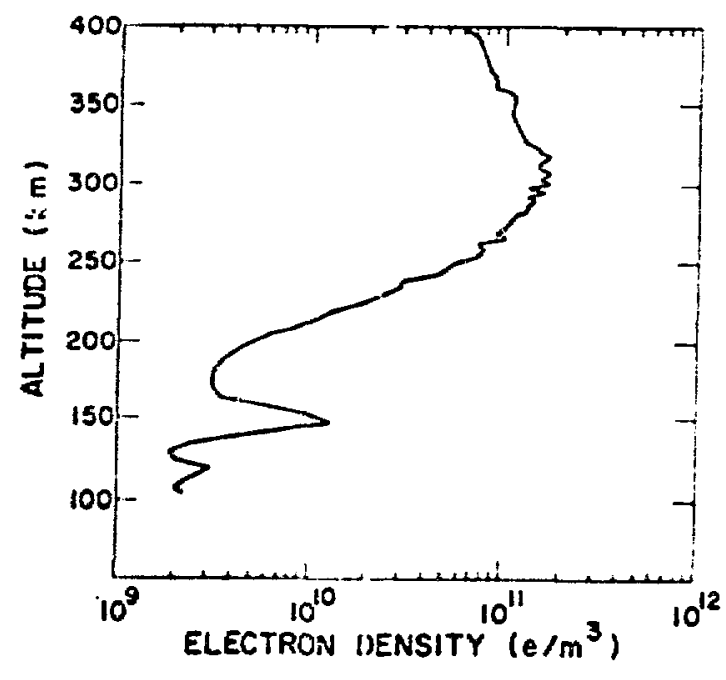

F1g. 2. Measured Electron Density Profile. 
VI. GEOMAGNETIC ORIENTATION OF RANDOM PULSES

The short pulses observed on the f 11 ter channels appeared to be correlated with magneic north or south when compared to the magnetometer trace. Of the 570 characteristic sets of pulses observed, most occurred above $90 \mathrm{~km}$. Pulses were counted only when they simultaneously occurred in two or more channels, and then as a one-pulse count. The frequency of occurrence was random with some occurring in bursts of two or three sets of pulses separated by about $0.8 \mathrm{~s}$, 60\% of which occurred in the 50-, 60\%, and 70-MHz channels. At times the pulses were seen simultaneously in all channeis, and at others in only a few of the channels. There were instances when a pulse was seen in one high-frequency channel and in one low-frequency channel only. The amplitude of about $80 \%$ of the pulses was between $80 \mathrm{mV} / \mathrm{m}$ and $100 \mathrm{mV} / \mathrm{m}$. The pulse duration was usually between 5 us and $400 \mu \mathrm{s}$ with some as long as $2 \mathrm{~ms}$. When the magnetometer indicated north or maximum, the antenna for the three lower frequency filtar channels was polnted $45^{\circ}$ counterclockwise as viewed from the bottom of the payload. Figure 3 is a histogram showing the orlentation of the pulses from all filter chamels with respect to the magnetometer trace. Figure 4 shows the location of either antenna with respect to magnetic north for all pulses. If an antenna was pointed east or west, and a pulse of electromagnetic energy was traveling down a field-line in the polar direction, the sensor system would have a 56-db gain over the time when the antenna was pointed north and a 24-db gain over the time when the antenna was pointed south. We have no way of deternining the direction of propagation of the pulse if indeed the pulse was traveling down a fleld-line as is strongly Indicated from these data.

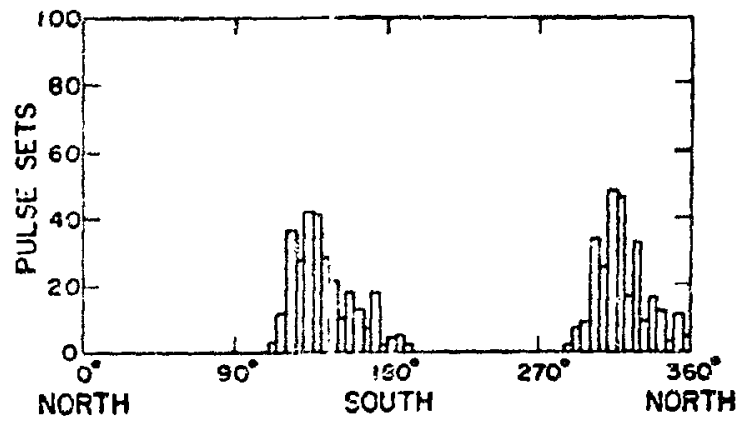

Fig. 3. Pulses Vs Magnetometer.

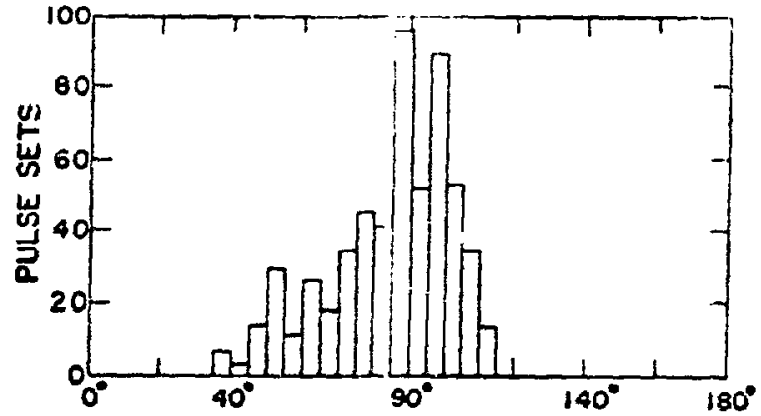

F1g. 4. Antenna Degrees from North or South Vs Pulse Sets. 
The probable radio-propagation conditions at the time of the rocket flight. are such that signals of about $20 \mathrm{MHz}$ or less could have been propagated by lonospheric refractions from remote points on the earth while propagation at $30 \mathrm{MHz}$ or higher could have been restricted to near line-of-sight distances. If this was the case, the number of signals from terrestrlal radio transmitters in the 20-MHz channel would have been much greater than the number of such signals in the higher frequency channels, while the rocket was below the F-region peak of the ionosphere. The 20-MHz signal from WWVH which is located about $8 \mathrm{~km}$ from the launch site is identiflable in the 20-MHz filter channel when the rocket is below the peak of the F-region. The measured ampiltude of the WhVH signal up to about $200 \mathrm{~km}$ is in reasonable agreement with signal estimates obtained from NBS publication 236 (NBS Frequency and Time Broadcast Services). The 20-MHz channel also shows some signals which tend to vanish high in the ionosphere. The other filter channels show much less variation with altitude. Nea: apogee, the signals in all channels are about the same in amplitude. It is believed that all channels were working properly during the flight, and that the pulses are not due to p-static or space-charging, ${ }^{4}$ or internal malfunctions.

\section{CONCLUSIONS}

The data examined strongly suggest that there are short bursts of electromagnetic energy traveling along the earth's magnetic-field-lines in the ionosphere. The amplitude of these pulses is slgnificant and contains a frequency content at least from $17 \mathrm{MHz}$ to $73 \mathrm{MHz}$. The VHF radiation present in the ionosphere is expected to consist of galactic noise, thunderstorm noise, and the signals from all radio transmitters roughly within line-of-sight distance of the rocket payload. The continual background notse when the rocket was above $30 \mathrm{~cm}$ observed in the data was about $4 \mathrm{mV} / \mathrm{m}$ or less peak-to-peak. All six filter ihannels saturated at about $200 \mathrm{mV} / \mathrm{m}$ peak and many of the channels were saturated at times by these short pulses. Missile charging and static discharge can be ruled out. Direct solar radiation could not have illuminated the rocket during the fiight, so a direct solar source is doubtful. Galactic sources appear douttul. This leaves ionospheric storms or an indirect solar source as the possiblf: source. Without further supporting evidence, the source of these pulses is unknown at present. 


\section{REFERENCES}

1. F. Horner, "Radio Noise In Space Ortginating In Natrral Texrestrlal Sorrces," Planet. Space Sc1., 13, 1137, (1965).

2. C. U. Benton et al., "EMP In the Ionosphere," Los Alamos Sclentific Laboratory report LA-4947 (September 1972).

3. G. Levy et al., "Measurement of Electric Fields in the Ionosphere," final report August 1966-September 1969, NASA report NiSA-CR-102471 (September 1969).

4. J. C. Axtell and T. C. Oakberg, "An Electrostat1c Charge Phenomenon Assoclated with Minuteman Missile Flights," The Boeing Compang report AFAL-TR-68-290 (September 1968). 